\title{
A simplified, practical, cost-effective surgical approach to sacrospinous colpopexy
}

\author{
Shalini Mahana Valecha ${ }^{1}$, Divija Dhingra ${ }^{2} *$
}

\begin{abstract}
${ }^{1}$ Department of Obstetrics \& Gynaecology, Employees State Insurance Post Graduate Institute of Medical Sciences and Research \& Model Hospital, Andheri, Mumbai, India

${ }^{2}$ Department of Obstetrics \& Gynaecology, Guru Teg Bahadur Hospital and UCMS, New Delhi, India
\end{abstract}

Received: 25 September 2015

Revised: 07 October 2015

Accepted: 29 October 2015

\section{*Correspondence: \\ Dr. Divija Dhingra, \\ E-mail: dwija23@gmail.com}

Copyright: (c) the author(s), publisher and licensee Medip Academy. This is an open-access article distributed under the terms of the Creative Commons Attribution Non-Commercial License, which permits unrestricted non-commercial use, distribution, and reproduction in any medium, provided the original work is properly cited.

\begin{abstract}
Sacrospinous ligament fixation (SSLF) or colpopexy or colpohysteropexy (when the uterus is conserved) for the treatment of pelvic organ prolapse as a procedure is more than 200 years old. Consequently, umpteen modifications vis-à-vis techniques, instrumentations, lighting options have been described. Most of these make a simple procedure needlessly complex, cumbersome and expensive. We have performed this procedure using a simplified, practical approach with readily available surgical instruments, suture methods and endoscopic lightening apparatus. The main aim of this paper is to highlight the surgical steps of sacrospinous colpopexy performed with simple and easily available routine surgical instruments.
\end{abstract}

Keywords: Foetal growth restriction, Foetal abdominal circumference, Doppler velocimetry, Screening, Diagnosis, Management

\section{INTRODUCTION}

Pelvic organ prolapse (POP) is a common problem affecting nearly 1 in every 10 women. By the age of 80 years, approximately $11-12 \%$ of women will have undergone surgery for pelvic floor dysfunction. ${ }^{1}$ With life-expectancy increasing steadily over the decades, this malady can be expected to increase. The extent of POP may vary, but most are symptomatic to various degrees; driving the patient to seek relief. Along with the medical aspects, POP also impacts the patient's social and marital life and hence has far reaching consequences. Causes are multifactorial ranging from vaginal delivery to obesity and advancing age. Anything that puts a strain on the uterovaginal support systems, causing them to weaken progressively and ultimately fail, will contribute to POP. The primary event is a loss of horizontal position of the levator plate making it more oblique or vertical, thus creating a funnel for the pelvic organs to herniate through. ${ }^{2}$

Logically, surgery to correct this should ensure that, the vaginal apex is restored to its rightful place.

1. The levator plate is brought back to its horizontal position. One method is to take a sound levator stitch during the posterior colpoperineorrhaphy procedure that follows most vaginal hysterectomies for POP.

2. The vaginal vault after hysterectomy or the vaginal apex with when the uterus remains in-situ is restored to its original position above the levator plate, so that during increases in abdominal pressure, it can rest snugly on the levator plate instead of descending down through the funneled pelvic floor. 
Sacrospinous fixation anchors the highest point of vagina to the coccygeous - sacrospinous ligament complex (C$\mathrm{SSL}$ ) in the heart of the true pelvis. C-SSL lies well above the levator plate and the stitch ensures that the vaginal apex stays above the plate. Post- hysterectomy vault prolapse bothers $0.5-1.8 \%$ of all patients who have undergone a hysterectomy and $11.6 \%$ of the patients with prior hysterectomy for uterine prolapse. ${ }^{3,4}$

The essentially, vaginal approach ensures access through a natural orifice, reduced operative time, quicker recovery, early discharge from hospital, rapid ambulation and therefore reduced overall cost. ${ }^{5}$

SSLF as a primary therapeutic procedure is done for vault prolapse following hysterectomy. ${ }^{6}$

In some patients it may be done as a secondary prophylactic procedure as the final step following completion of hysterectomy to ensure that future vault prolapses does not develop. It may also be done as a uterine suspension procedure for patients who wish to retain their uteri. $^{7-9}$

The main objective of this article is to highlight on the surgical steps of sacrospinous ligament fixation for the treatment of pelvic organ prolapse using simple and readily available surgical instruments, thus making this procedure cost-effective and more practical.

\section{METHODS}

After discussing the nature of the procedure with the patient and obtaining consent, the patient is prepared and the primary hysterectomy completed, typically under regional anesthesia. Vault may be closed after hysterectomy or may be left open until SSLF is complete. No extensive pre-operative preparation is required. Light diet on the day before surgery and mild oral or rectal laxatives on the night before surgery ensure empty rectum on the surgical table.

\section{Operative procedure}

Ischial spine is palpated. C-SSL complex is palpated along its length. If unilateral fixation is chosen, we prefer the right side primarily because the surgeon's dominant hand being the right hand makes it comfortable. Also the rectum is easier to deflect on the patient's left. Studies have shown equal efficacy between unilateral and bilateral SSLF and infact, greater rates of post-operative anterior compartment prolapses have been reported following bilateral fixation. ${ }^{10}$

Challenges in performing the surgery are best understood based on the steps of the procedure;

a. Difficulty in accessing and dissecting the para-rectal space especially in previously operated patients. E.g. cases of vault prolapsed following hysterectomy. b. Difficulty in visualizing the CSSL. E.g. Obese patients. In overweight patients all fascial spaces tend to be laden with fat pads; including the pararectal and ischiorectal fossae.

c. Difficulty in holding an adequate chunk of ligament at the appropriate site for secure ligation.

d. Difficulty in tying sutures through the ligament and vaginal apex.

We shall describe our technique in sequential steps as is evidenced during the actual surgery. All the surgeries were performed by an experienced surgeon specialized in sacrospinous fixation.

\section{Approach to the CSSL complex}

The sacrospinous ligament is accessed vaginally through the pararectal space. A vertical incision in the lax, rugae free region just lateral to the enterocele sac is preferred. The length of the incision may be delineated by holding the edges with Allis tissue holding forceps. Blunt dissection with the right index finger in the medial direction deflects the enterocele sac with its contents off the vaginal wall. Further finger dissection is done in a lateral, posterior and inferior approach, aiming towards the ischiorectal fossa. The rectal pillar is thus reflected medially and pararectal space entered safely. Venous plexuses abound in this treacherous territory and caution is advised. If bleeding ensues, packing a sponge for pressure suffices. Occasionally, vascular clips may be required. $^{11}$ Occasionally, Metzenbaum scissors are required to develop this space. ${ }^{12}$ This technique involves an appreciably smaller vaginal incision, placed high up, leaving no trace of surgery at the introitus.

Alternatively; if posterior colpoperineorrhaphy is also being done, the same incision started at the introitus may be extended up around the enterocele sac and the pararectal space entered in a similar fashion. The rectum is delineated medially by doing frequent per-rectal examinations.

\section{Visualization of the CSSL complex}

We use our "three strategically placed Dever's retractors" to visualize the CSSL complex as shown in Figure 1. The first Dever placed supero-medially elevates the pelvic contents enclosed within the enterocele sac along with the vesical bulge. The second Dever, positioned inferomedially retracts the rectum. The third and final Dever stationed infero-laterally retracts the contents of the ischiorectal space including the substantial pad of fat. Adequate length of the CSSL complex is thus exposed for suturing. ${ }^{13}$ Thin bladed Dever's retractors are readily 
available on any laparotomy tray. We used an innovatory method of using the endoscopic light cable held by an assistant or nurse to illuminate this deep space for the purpose of exposure and suture placement as shown in Figure 2. Authors have described use of other retractors like Breisky- Navratil retractors, Lighted Miya retractors, Heaney's Simon retractors. ${ }^{14,15}$ These all are expensive, not readily available and special procurement adds unnecessary cost to the surgery.

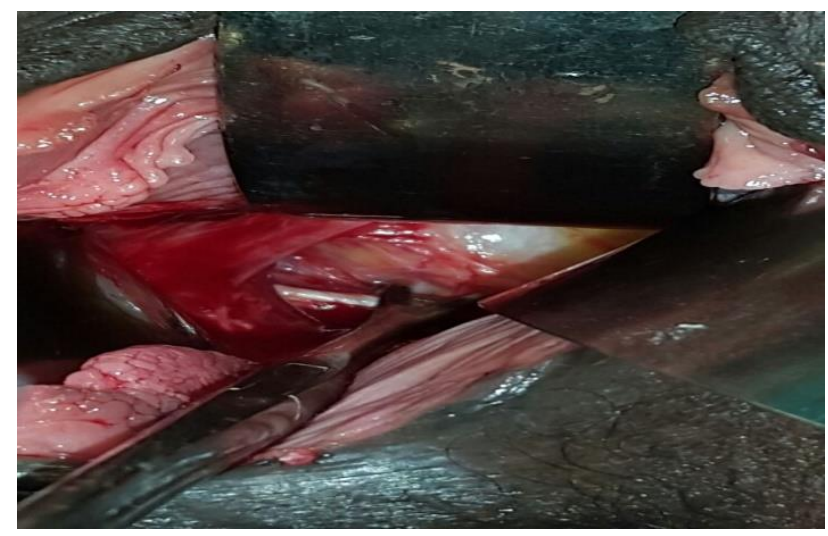

Figure 1: Ligament exposed using three Dever retractors, held with long Babcock forceps.

\section{Holding the CSSL complex}

With the pararectal space now dissected, retractors in place and using endoscopic light, the CSSL is clearly visualized. Retractor tips may be used to clear adventitial tissue off the ligament till the white glistening thickened structure is seen running in a latero-medio-posterior direction from ishchial spine down towards sacrum and coccyx. We use a long Babcock forceps to take a firm hold of ligament, about $2.5 \mathrm{~cm}$ lateral to the easily palpated ischial spine as shown in figure 1. Alternatively a long Allis tissue holding forceps may be used. Tugging on the forceps moves the patient slightly. This ensures a good chunk of ligament and not fat is held. Both these instruments are readily available on all surgical trays.

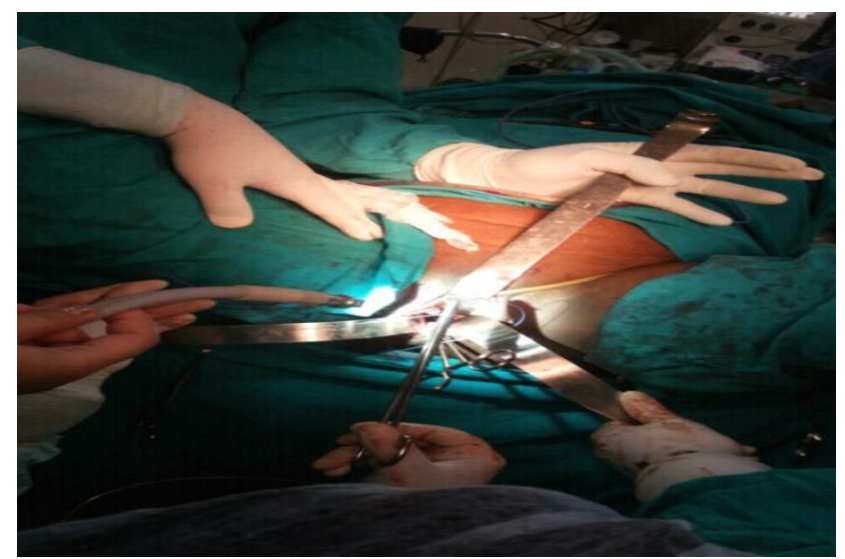

Figure 2: Use of endoscopic light to illuminate the space during suturing.

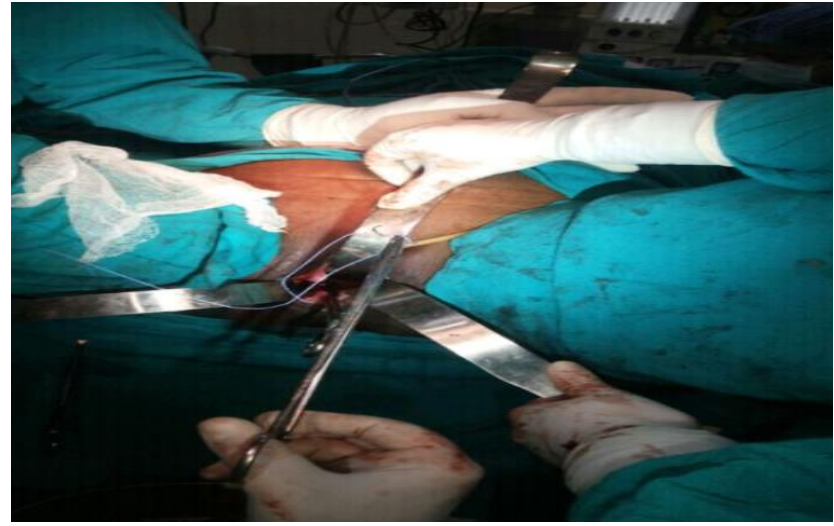

Figure 3: The three strategically placed Dever retractors and no. 1 vicryl on a stout Mayo's needle held with an ordinary needle holder.

\section{Placing sutures through the CSSL complex}

Authors have described use of various suture devices to place a suture through the CSSL complex like Miya Hook Ligature carrier, Capio Suture Capturing Device, Shutt suture punch system with Sharp technique, Dechamps ligature carrier, Pinnacle device etc. ${ }^{16-19}$ Schlesinger used the auto suture Endostitch device. ${ }^{17,20}$ These are all expensive instruments, not routinely kept on surgical trays. Infact, most operating rooms do not have these uncommon equipments. We used a half circle Mayo's stout cutting needle, No. 2 (36 mm) or No. 1 (45 $\mathrm{mm})$ or No. 1/0 (57 mm), all of which are easily available on all operating room trolleys and selection may be made depending upon amount of space in the cavity. It is held with a routine simple needle holder to secure the ligament as shown in figure 3 . In some cases, we used No. 1 nonabsorbable Prolene (Polypropylene Monofilament) suture and in other cases No. 1 absorbable Vicryl (Braided coated Polyglactin suture. Either a single figure of eight stitch was applied taking a substantial chunk of CSSL or two separate straight sutures were applied. Again, these needles are available in all operation theatres and are relatively inexpensive compared to the fancy suture system described in the literature. A slight tug on the sutures moves the patient, confirming that the ligament has been securely held.

These sutures are then anchored to the vaginal apex and tightened. Apex gets drawn high up above the levator plate and gets firmly attached to the CSSL. No vagina is cut; therefore good vaginal length remains, facilitating sexual activity. ${ }^{21}$ An average time of 20-30 minutes and blood loss of 30-50 cc was seen in our series. ${ }^{9}$ We used hemostatic solutions like Tisseel (VH Baxter Healthcare, IL, USA) or Evicel Fibrin glue (All human fibrin sealant) where the dissected space showed oozing. For a sharper haemorrhage, flowable gelatin-thrombin preparations like Floseal (Hemostatic matrix) or Surgiflow (Flowable gelatin matrix) is beneficial. However, these add to costs and were used in exceptional cases. Gauze packing of the 
vagina for 12-24 hours is a last step for ongoing pressure hemostasis.

\section{CONCLUSIONS}

Suspension of the vaginal apex to the sacrospinous ligament is one of the most well-accepted and effective vault suspension procedures. Literature has described many modifications and a myriad of instruments and ligature systems for sacrospinous ligament fixation, making an essentially simple and cheap procedure, unnecessarily complex and expensive. This defeats the very purpose of a surgical operation. Limiting the cost of a surgical procedure, continues to be a desirable objective for surgeons and patients alike and it has been our constant endeavor to replace expensive instrumentations with cheaper alternatives. The simplified technique systematically described in this publication uses instruments which are readily available in all surgical theatres, keeping this objective in mind. Both surgeons and patients stand to benefit from such modifications.

Funding: No funding sources Conflict of interest: None declared

Ethical approval: Not required

\section{REFERENCES}

1. Olsen AL, Smith VJ, Bergstrom JO, Colling JC, Clark AL. Epidemiology of surgically managed pelvic organ prolapse and urinary incontinence. Obstet Gynecol. 1997;89(4):501-6.

2. Berglas B, Rubin IC. Study of the supportive structures of the uterus by levatormyography. Surg Gynecol Obstet. 1953;97(6):677-92.

3. Marchionni. True incidence of vaginal vault prolapse: thirteen years of experience. J Reprod Med. 1999;44(8):679-84.

4. Dallenbach P, Kaelin-Gambirasio I, Jacob S. Incidence rate and risk factors for vaginal vault prolapse repair after hysterectomy. Int Urogynecol J Pelvic Floor Dysfunction. 2008;19:1623-29.

5. $\mathrm{Ng} \mathrm{CC}$, Han WH. Comparison of effectiveness of vaginal and abdominal routes in treating severe uterovaginal or vault prolapse. Singapore Med J. 2004;45(10):475-81.

6. Valecha SM, Dhingra D. Unilateral Sacrospinous Colpohysteropexy Uterus Preserving Surgery for Uterovaginal Prolapse. Medical Science. 2014;5(18):77-80.

7. Zucchi. Uterus preservation in pelvic organ prolapsed surgery. Nature Reviews Urology. 2010;7(11):626-33.
8. Maher. Uterine preservation or hysterectomy at sacrospinous colpopexy for uterovaginal prolapses. Int Urogynecol J. 2001;12:381-5.

9. Valecha SM, Dhingra D. A Systematic Review of A Series of Cases of Vaginal Vault Prolapse Treated With Sacrospinous Ligament Fixation Global Journal For Research Analysis. 2014;3(9).

10. David-Montefiore E, Barranger E, Dubernard G, Nizard V, Antoine JM, Daraï E. Functional results and quality-of-life after bilateral sacrospinous ligament fixation for genital prolapse. Eur J Obstet Gynecol Reprod Biol. 2007;132(2):209-13.

11. Cruikshank SH, Muniz M. Outcomes study: a comparison of cure rates in 695 patients undergoing sacrospinous ligament fixation alone and with other site specific procedure a 16-year study. Am J Obstet Gynecol. 2003;188:1509e15.

12. Hurt WG. Surgical Instruments and Drains. In Gilstrap Lc III, Cunningham FG, Vandorsten JP (eds) Operative Obstetrics. $2^{\text {nd }}$ ed. New York, Mc Graw-Hill. 2002:17.

13. Valecha SM, Dhingra D. A Prospective Observational Study of Sacrospinous Ligament Fixation. American Journal of Advanced Drug Delivery. 2014;2(4):493-502.

14. Carey MP, Slack MC. Transvaginal sacrospinous colpopexy for vault and marked uterovaginal prolapse. BJOG: An International Journal of Obstetrics \& Gynaecology. 1994:536-40.

15. Ginsberg DA. Vaginal vault prolapse: evaluation and repair. Current urology reports. 2003:404-8.

16. Miyazaki FS. Miya hook ligature carrier for sacrospinous ligament suspension. Obstet Gynecol. 1987;70:286-8.

17. Manning JA, Arnold P. A review of six sacrospinous suture devices. Australian and New Zealand Journal of Obstetrics and Gynaecology. 2014:558-63.

18. Sharp TR. Sacrospinous suspension made easy. Obstet Gynecol. 1993;82(5):873-5.

19. Cayrac M, Letouzey V, Ouzaid I, Costa P, Delmas V, de Tayrac R. Anterior sacrospinous ligament fixation associated with paravaginal repair using the Pinnacle ${ }^{\mathrm{TM}}$ device: an anatomical study. Int Urogynecol J. 2012;23(3):335-40.

20. Schlesinger RE. Vaginal sacrospinous ligament fixation with the Autosuture Endostitch device. Am J Obstet Gynecol. 1997;176(6):1358-62.

21. Given FT, Muhlendorf IK, Browning GM. Vaginal length and sexual function after colpopexy forcomplete uterovaginal eversion. Am J Obstet Gynecol. 1993;169:284-7.

Cite this article as: Valecha SM, Dhingra D. A simplified, practical, cost-effective surgical approach to acrospinous colpopexy. Int J Reprod Contracept Obstet Gynecol 2015;4:1682-5. 